\title{
O Controle do Câncer do Colo do Útero: um Desafio para a Saúde Pública
}

\author{
Control of Cervical Cancer: a Challenge to Public Health \\ Control del Cáncer Cervicouterino: un Reto para la Salud Pública
}

\author{
Instituto Nacional de Câncer José Alencar Gomes da Silva (INCA); Fundação Oswaldo \\ Cruz (Fiocruz). \\ Rio de Janeiro, RJ: 2014. 198p. \\ ISBN: 978-85-7318-252-1 (versão impressa) / 978-85-7318-251-4 (versão eletrônica)
}

Taís Facina ${ }^{1}$

Este livro trata de um importante tema da oncologia, o câncer do colo do útero, sob uma perspectiva histórica. Por meio de depoimentos orais, resgata a história do controle dessa doença no país, oferecendo ao leitor uma base sólida para uma reflexão atual.

A série Depoimentos para a história do controle do câncer no Brasil é uma iniciativa do projeto História do Câncer - atores, cenários e políticas públicas, uma parceria entre o Instituto Nacional de Câncer José Alencar Gomes da Silva (INCA) e a Casa de Oswaldo Cruz, da Fundação Oswaldo Cruz (COC/Fiocruz).

Por meio de entrevistas realizadas com profissionais que tiveram uma efetiva participação em iniciativas para o controle do câncer do colo do útero no país, o livro traz diferentes ângulos de visão e mostra o cenário surgido a partir da década de 1960, quando aconteceu o deslocamento da abordagem da doença individual para o campo da saúde pública.

Foi nessa época, a partir dos estudos de George Nicholaus Papanicolaou, que se comprovou a possibilidade de diagnosticar alteraçôes citológicas prévias à ocorrência do câncer, por meio da análise microscópica de amostras do esfregaço vaginal, o exame que hoje é conhecido como Papanicolaou. A partir de então, diversas açôes têm sido estruturadas para a detecção precoce do câncer do colo do útero, tendo em vista que esse tipo de câncer é totalmente prevenível se as lesôes pré-cancerígenas forem detectadas e tratadas precocemente. Ainda assim, o câncer do colo do útero é o terceiro mais comum entre a população feminina brasileira (sem considerar o câncer de pele não melanoma), segundo dados do INCA, e a quarta causa de morte de mulheres por câncer no país. Por isso, as açóes de rastreamento e detecção precoce são tão importantes. Segundo a Organização Mundial da Saúde (OMS), é possível reduzir a incidência dessa doença em $60 \%$ a $90 \%$, em média, se for mantida uma cobertura do exame de rastreamento para $80 \%$ da população-alvo e garantindo diagnóstico e tratamento adequados dos casos alterados.

O primeiro entrevistado, o médico Mario Jaconianni (in memoriam), foi pioneiro na organização de uma escola de capacitação de citotécnicos, fundador do Programa Integrado de Tecnologia em Citopatologia (Pitec), atual Seção Integrada de Citopatologia (Sitec) do INCA. A entrevista foi realizada no momento em que ele tinha 86 anos de idade, fato que concedeu alguns lapsos de memória e certa brevidade à conversa, mas que não deixou de transparecer, como relataram os organizadores do livro, "uma notável demonstraçáo de inteligência, modéstia, bom humor e sensos de oportunidade e missão".

Outro entrevistado, Luiz Carlos Zeferino, professor titular da Universidade Estadual de Campinas (Unicamp), foi um dos organizadores de uma das experiências pioneiras da década de 1960, o início do rastreamento citológico do câncer do colo do útero. Em 1983, junto a um grupo de docentes dessa universidade, implantou o Centro de

1'Jornalista, pós-graduada em "Produção do Livro”, editora de publicaçóes científicas no Instituto Nacional de Câncer José Alencar Gomes da Silva (INCA). 
Controle de Câncer Ginecológico e Mamário (Cecan), que depois se transformou no Programa de Assistência Integral à Saúde da Mulher (PAISM), que, por sua, vez, originou o Centro de Atenção Integral à Saúde da Mulher (CAISM).

Durante sua passagem como diretor técnico-científico da Fundação Oncocentro de São Paulo (Fosp), projeto da secretaria estadual de saúde do Estado de Sáo Paulo, foram reativados e expandidos os cursos de formação de citotécnicos e a capacitação de enfermeiros para coletar material para o exame de Papanicolaou. Durante sua gestão como coordenador do programa estadual de controle de câncer, foi criado o serviço de colposcopia no Estado.

A entrevistada Lucilia Maria Gama Zardo, ex-diretora da Seção Integrada de Citopatologia (Sitec) do INCA, é uma profissional com longa trajetória e dedicação na citopatologia, área considerada central para a organização e o bom êxito dos programas de rastreamento.

Em sua entrevista, Lucilia conta, por exemplo, uma das versões aceitas sobre a criação da escovinha para exploração do canal cervical, na década de 1980, quando a colheita do preventivo era feita só da parede lateral na colheita vaginal e da ectocérvice. $\mathrm{Na}$ endocérvice, era introduzido o cotonete (swab), que absorvia toda a secreção, mas não pegava as células. "O Dr. Artur [Campos da Paz] fumava cachimbo. Então ele pegou a escovinha de limpeza para cachimbo e a alongou, ou colocou uma pinça, não sei exatamente como, e passou a utilizá-la no canal, para poder explorar a endocérvice, que é sítio de lesão. [...] Então, ele fez contato com empresas e desenvolveu a escovinha Campos da Paz", conta a médica.

Lucilia participou ativamente da incorporação da Fundação Pioneiras Sociais ao INCA e de toda organização estrutural que aconteceu depois, com atividades importantes para o cenário do controle do câncer, como a padronização da nomenclatura dos exames citopatológicos e a questão do credenciamento e controle de qualidade dos laboratórios de citopatologia que atuariam no Viva Mulher.

Além da visão de gestores na área de controle do câncer do colo do útero, o livro também traz o ponto de vista de quem sempre esteve envolvido no dia a dia dessa luta, como o analista de câncer do INCA, Marcos André Félix da Silva, com extensa experiência em programas de controle.

Enfermeiro de formação e com experiência em detecção precoce, Marcos participou ativamente da equipe do Programa Nacional de Controle do Câncer do Colo Uterino - Programa Viva Mulher. Nesta entrevista, faz um relato detalhado de toda sua implantação e funcionamento até sua extinção. Marcos também foi professor do curso de formação de citotécnico da Sitec, supervisor da Área de Ensino de Enfermagem do INCA e coordenador do Curso de Especialização em Enfermagem Oncológica do Instituto. Atualmente, trabalha na Divisão de Detecção Precoce e Apoio à Organização de Rede da Coordenação de Prevenção e Vigilância (Conprev) do INCA. Sobre essa atuação, Marcos fala sobre o Sistema de Informação do Câncer do Colo do Útero (Siscolo), a vacina contra o Papilomavírus Humano (HPV) e a formação e o mercado de trabalho dos citotécnicos, entre outros assuntos.

Já o relato de Maria do Espírito Santo Tavares dos Santos, a Santinha, traz a visão não governamental sobre o assunto, de uma profissional de saúde historicamente engajada em movimentos sociais, em especial na luta pelo direito das mulheres.

$\mathrm{Na}$ década de 1970, levou a questáo da mulher para uma reunião do Partido Comunista e começou então seu engajamento em diversos movimentos sociais. Como membro da comissão organizadora, participou da conferência de direitos da mulher em Pequim, na China, na década de 1980, quando foi firmado o compromisso do governo brasileiro em relação à saúde da mulher, inserindo os cânceres de colo do útero e mama como compromissos de governo.

Por último, uma extensa e esclarecedora entrevista, com trechos de uma palestra proferida especialmente para o livro, de um dos coordenadores do Programa Viva Mulher e atual pesquisador e coordenador-adjunto do Programa de Pós-Graduação em Oncologia do INCA, Luiz Claudio Santos Thuler. No INCA, já trabalhou como médico da Comissão de Controle de Infecção Hospitalar, chefe da Divisão de Epidemiologia, chefe da Divisão de Ações de Detecção Precoce, editor científico da Revista Brasileira de Cancerologia e coordenador de Educação. Em sua palestra, didaticamente estruturada, Thuler fala sobre as diferenças entre prevençóes primária e secundária, rastreamento e diagnóstico precoce, as primeiras campanhas de controle do câncer do colo do útero, infecção pelo HPV e vacina, entre diversos outros temas relacionados ao controle do câncer do colo do útero.

Assim, reunindo os diversos pontos de vista e a vasta experiência de importantes personagens da história do controle do câncer do colo do útero no país, este livro é um compêndio fundamental para se conhecer o passado e guiar futuras açôes na área de prevenção, diagnóstico precoce e controle do câncer do colo do útero. 